\title{
TITLE:
}

\section{Declining Sustainability: The Case of Shopping Trip Energy Consumption}

\section{AUTHOR(S):}

Kitamura, Ryuichi; Sakamoto, Kyotaro; Waygood, Owen

\section{CITATION:}

Kitamura, Ryuichi ... [et al]. Declining Sustainability: The Case of Shopping Trip Energy Consumption. International Journal of Sustainable Transportation 2008, 2(3): 158-176

\section{ISSUE DATE:}

2008-07

URL:

http://hdl.handle.net/2433/128873

\section{RIGHT:}

(c) 2008 Informa plc; この論文は出版社版でありません。引用の際には 出版社版をご確認ご利用ください。; This is not the published version. Please cite only the published version. 


\title{
DECLINING SUSTAINABILITY: The CASe of Shopping Trip Energy Consumption
}

\author{
Ryuichi Kitamura $^{1}$, Kyotaro Sakamoto ${ }^{2}$ and Owen Waygood ${ }^{1}$ \\ ${ }^{1}$ Department of Urban Management \\ Kyoto University \\ Katsura Campus \\ Nishikyo-ku, Kyoto 615-8540 \\ Japan \\ rkitamura@trans.kuciv.kyoto-u.ac.jp \\ ${ }^{2}$ Recruit Company \\ Harvis ENT 22F \\ 2-2-22 Umeda \\ Kita-ku, Osaka 530-0001
}

\begin{abstract}
As typical shopping behavior changed from foot-based visits to neighborhood shopping streets or corner grocery stores to auto-based visits to large-scale retail stores, shopping trip energy consumption increased substantially in the Osaka metropolitan area between year 1970 and 2000. Underlying this phenomenon are, among others, progress of motorization, declining household size, and diminishing households with a homemaker. The effects of these and other factors are examined through an analysis of variance of large-scale household travel survey data from 1970 and 2000. It is shown that changes in demographics and socio-economics alone would not have produced the observed magnitude of increase in shopping trip energy consumption. The more substantial contributor has been structural change, which has presumably been caused by the urban system adjusting its elements-land use, transportation networks, facility location, retail systems etc. - to adapt to increased ownership and use of the automobile.
\end{abstract}




\title{
DECLINING SUSTAINABILITY: The CASe of Shopping Trip Energy Consumption
}

\author{
Ryuichi Kitamura, Kyotaro Sakamoto and Owen Waygood
}

\section{Introduction}

The progress of motorization and the resulting dominance of automobility (Urry, 2005) are adversely affecting the sustainability of tightly-knit, once transit-oriented metropolitan areas of Japan. In the Osaka metropolitan area, the second largest in Japan and the study area of this investigation, the average energy consumed per shopping trip increased 5.81 times from $193 \mathrm{kcal}$ in 1970 to $1,122 \mathrm{kcal}$ in $2000 .^{1}$ The average energy consumption of person trips for all purposes in the area increased 1.48 times from 1,460 kcal to 2,160 kcal in the same period.

On the per-person basis, average shopping trip energy consumption increased 6.24 times from $44.9 \mathrm{kcal} /$ person/day in 1970 to $280 \mathrm{kcal} /$ person/day in 2000 . Total travel energy consumption, on the other hand, increased 1.49 times from 3,461 to 5,166 kcal/person/day. On the per-household basis, average shopping trip energy consumption increased 5.48 times from 132 to $724 \mathrm{kcal} /$ household/day, while total travel energy consumption increased 1.30 times from 9,741 to $12,622 \mathrm{kcal} /$ household/day. The average share of shopping trip energy consumption in total travel energy consumption per person was a mere $1.36 \%$ in 1970, which increased to $5.73 \%$ in 2000 . Clearly, the efficiency of the area has declined as far as household energy consumption for travel is concerned. ${ }^{2}$ The increase in shopping trip energy consumption is particularly large and deserves further attention.

In its absolute value, shopping trip energy consumption is still small relative to those for trips with other purposes, most notably commuting. Nonetheless, its rate of increase by far exceeds that for all person trips. Indeed shopping trips are becoming a sizeable component of the travel energy consumed by urban households. It is likely that energy consumption for other non-work trips is also increasing from similar underlying causes. It is then imperative that reasons for this notable increase be examined for better prediction of future trends in household travel energy consumption, and for more informed formation of policy measures for reduced travel energy consumption.

This study is such an attempt where results of repeated large-scale households travel surveys are deployed to determine the causes of the increase in shopping trip energy consumption. It is argued in this paper that the increase in the energy consumption for shopping trips cannot be attributed solely to changes in household characteristics, such as automobile ownership and household size. Rather, structural changes, which presumably represent the transformation of the Osaka metropolitan area in its adaptation to automobile-oriented person travel, account for a larger fraction of the increase. This overall trend has reduced the sustainability of the area with respect to transportation energy consumption.

\footnotetext{
${ }^{1}$ Trip energy consumption is estimated in this study based on large-scale household travel surveys conducted in the Kei-Han-Shin metropolitan area of Japan. Details are described in the next section.

2 The discussion of this study is limited to household sector and to intra-urban travel; energy consumption for freight transportation and that for inter-city travel by household sector are not considered.
} 
Sustainable transportation may be described in its simplest form as attempts to balance economic, environmental, and social impacts. A more detailed description of sustainable transportation can be found in Litman (2005). Sustainable indicators are one form of measuring the sustainability of a transportation system (Litman, 2005). A set of indicators should examine all three aspects of sustainability. Applied to a span of time, indicators can show progress away or towards increased sustainability. This paper examines the impacts that motorization of the Osaka metropolitan area has had on energy consumption for shopping trips. Using as an indicator the amount of energy used to travel to shopping opportunities, this study shows that the structural impacts that increasing automobility has caused alone represent over a three fold increase in energy consumption for this activity, moving away from sustainability.

There is debate over how motorization affects land use, especially in North America where its impacts have been the most significant (Crane and Crepeau, 1998). One side argues that mixed land use and increased density can reduce motorized travel (Ewing, 1997), while other researchers have found that shorter distances may create more trips, and that through trip chaining with a private vehicle there would be less energy consumption (Gordon and Richardson, 1997). However, for the Osaka metropolitan area, it was found that commuters that used transit chained trips more often than those who commuted by private vehicle (Susilo and Kitamura, 2007). Part of the reason for this may be that since many people exit a train or transit station, stores and other opportunities naturally cluster in the vicinity, creating an environment inductive of trip chaining. This paper to a certain degree shows that as the population of a metropolitan area spreads out, lowering the density, there are increases in energy consumption, not the opposite as suggested by Gordon and Richardson.

Gordon and Richardson (1997) wrote, "the link between high-density development and reduced VMT (vehicle miles traveled), and hence reduced energy consumption, is by no means clear." This paper amongst others (e.g., Newman and Kenworthy, 1999; Susilo and Kitamura, 2007) shows that energy consumption is quite distinctly different between the high-density development of urban areas and the surrounding suburban and low-density areas.

This paper is organized as follows. Section 2 offers a brief description of the study area, the household travel survey data, and the method of estimating trip energy consumption used in this study. Profiles of household travel energy consumption in the study area are also given in relation to vehicle ownership and commuting. The increase in shopping trip energy consumption in the study area between 1970 and 2000 is documented in Section 3. It is shown that shopping trip energy consumption increased much more than the energy consumption for trips of all purposes. Conceivable reasons for this increase are discussed in Section 4. As primary contributing factors, motorization, suburbanization, decreasing household size, decreasing number of households with a homemaker, and increasing affluence are discussed. Based on this discussion, an analysis of variance is performed using household shopping trip energy consumption and shopping trip energy consumption per person as the dependent variable. Results are reported in Section 5. An important conclusion that emerged is that, as noted above, changes in demographic and socio-economic characteristics in the study area alone would not have produced the magnitude of increase in shopping trip energy consumption as observed in the study, and structural change- which presumably represents the increasingly prevailing automobility in the Osaka metropolitan area-has been the more central contributor. Section 6 is a brief summary. 


\section{Study Area Characteristics and Data}

The study area is the Kei-Han-Shin metropolitan area (hereafter the "Osaka metropolitan area"), the second largest metropolitan area of Japan comprising three major cities of Kyoto, Osaka and Kobe (Table 1). The area is characterized by dense and mixed land use patterns. There are some reasons why this may be: absence of forceful zoning regulations, high value placed on being close to transit stops, and restrictions based on balancing land-available with development. However, suburbanization is evident.

Table 1. 2000 Profiles of the Study Areas

\begin{tabular}{|l|r|}
\hline Area $\left(\mathrm{km}^{2}\right)$ & 9,223 \\
Population density (inhabitants $\left./ \mathrm{km}^{2}\right)$ & 1,975 \\
Residential population & $18,217,017$ \\
Total number of employees & $7,858,106$ \\
Primary-industry employees & 71,999 \\
Secondary-industry employees & $2,201,218$ \\
Tertiary-industry employees & $5,584,890$ \\
\hline
\end{tabular}

Decentralization is less significant than evident in North America. It is largely limited to retail employees and the centralized population has not significantly changed since the 1970s. The population of the surrounding areas however has significantly increased. This has created a change in the moment arm based on the mass center of the area from $30.98 \mathrm{~km}$ in 1970 to $32.56 \mathrm{~km}$ in 2000 (Kitamura and Susilo, 2005). Motorization is most evident in these new areas.

Motorization in the Osaka metropolitan area has been primarily confined to emerging areas and suburbs built over the last thirty years. The central areas and those with mixed land uses have remained at roughly 0.5 car per household, but the suburbs have higher rates with older suburbs having a rate of 0.77 car per household, up to emerging areas with 1.37 cars per household. The area average is 0.97 car per household, which is still below the national average of 1.12. The travel time expenditure increases are largest in the newer areas (Kitamura and Susilo, 2005).

Accessibility levels for the automobile in the Osaka Metropolitan area are roughly twice as large as those by rail (Kitamura et al., 2003), yet transit commuters were "more mobile and had higher levels of activity engagement" than auto commuters (Susilo and Kitamura, 2007). Commute times in the area are basically stable at thirty-six minutes. Total travel time for people living in autonomous cities, mixed commercial cities and commercial cities has remained stable, but for those living in the suburbs it has increased by $16.8 \%$ (Kitamura and Susilo, 2005). ${ }^{3}$

Energy consumption for travel is estimated in this study using results of large-scale household travel surveys conducted in the Osaka area in 1970 and 2000. In the analysis of this study, the area is divided into 194 geographical zones, which are classified into urban, suburban, and unurbanized areas. Energy consumption is estimated for those sample individuals who resided in the study areas.

${ }^{3}$ The scheme used to classify urban areas was developed by Fukui (2003) and is briefly described in Kitamura and Susilo (2005). 
The amount of energy consumed for each trip made by these sample individuals is estimated based on the consumption rates by travel mode proposed by Matsuhashi (2000) for Japanese urban areas (Table 2). When a trip involved multiple modes, the energy consumed is estimated for each segment of the trip which was made by a single mode, then summed together as an estimate of the energy consumed by the trip. Since energy consumption by auto depends on traffic condition, both travel distance ${ }^{4}$ and travel time are used to estimate the energy consumed. Non-motorized trips (primarily those by bicycle and on foot) and trips made to or from outside the study area are excluded from the analysis of this study. The amounts of energy consumed in the set of trips made by the members of a household are added together to estimate household energy consumption for travel.

Table 2. Energy Consumption Rates by Travel Mode Used in the Analysis

\begin{tabular}{|l|c|c|c|}
\hline \multirow{2}{*}{} & \multicolumn{3}{|c|}{ Consumption Rate per Passenger } \\
\cline { 2 - 4 } & $\begin{array}{c}\text { Time-based } \\
(\mathrm{kcal} / \mathrm{min})\end{array}$ & $\begin{array}{c}\text { Distance- } \\
\text { based } \\
(\mathrm{kcal} / \mathrm{km})\end{array}$ & $\begin{array}{c}\text { Composite } \\
(\mathrm{kcal} / \mathrm{km})\end{array}$ \\
\hline Moped & - & - & 105 \\
Motorcycle & - & - & 241 \\
Taxi & 400 & 1766 & 2131 \\
Subcompact car & 99 & 439 & 512 \\
Passenger car & 124 & 545 & 658 \\
Commercial truck & 176 & 949 & 1103 \\
Charter bus & 16 & 128 & 125 \\
Bus & 42 & 334 & 326 \\
Railway & - & - & 104 \\
\hline
\end{tabular}

Source: Matsuhashi (2000)

Household travel energy consumption is broken down by household vehicle ownership in Table 3 for year 2000. Quite notably, households with three or more vehicles consumed approximately 10 times as much transportation energy as did households without a vehicle. Energy consumption per person also varies greatly by household vehicle ownership. It is evident from this tabulation that motorization is a significant contributor to energy consumption for travel by households.

Energy consumption for travel is also closely related to commuting. In Table 4, households are grouped into: commuting households in which at least one commute trip was reported by household members on the survey day, and non-commuting households in which no commute trip was reported for that day. A non-commuting household includes people that work at home, and also people who work, but did not commute on the survey day. It can be seen that household energy consumption increases with the number of commuters and also with the number of household members. At the per-person level, a member of a commuting household consumed about $80 \%$ more energy for travel than a member of a non-commuting household. Of the total transportation energy consumed by a household, $27.5 \%$ are consumed to commute to work. Note that these statistics do not include trips from work back to home. It is evident that commute trips constitute a significant fraction of household energy consumption for travel, warranting emphasis on travel demand management (TDM) measures that target commute trips.

${ }^{4}$ Centroid-to-centroid distance is used in this study as trip distance. 
Table 3. Travel Energy Consumption in 2000 by Household Vehicle Ownership

\begin{tabular}{|l|c|c|}
\hline $\begin{array}{l}\text { Number of } \\
\text { Household } \\
\text { Vehicles }\end{array}$ & $\begin{array}{c}\text { Per } \\
\text { Household }\end{array}$ & Per Person \\
\hline 0 & 4,356 & 2,447 \\
1 & 18,148 & 6,535 \\
2 & 30,023 & 8,743 \\
3 or more & 39,380 & 9,284 \\
\hline
\end{tabular}

Table 4. Travel Energy Consumption by Household Commute Characteristics

\begin{tabular}{|l|ccc|}
\hline & $\begin{array}{c}\text { Per } \\
\text { household }\end{array}$ & Per Person & $\begin{array}{c}\text { Fraction of } \\
\text { Commute } \\
\text { Trip Energy }\end{array}$ \\
\hline Non-commuting households & 7,626 & 3,990 & - \\
\hline Commuting households & 22,102 & 7,225 & $27.5 \%$ \\
\hline 1 worker, 1 member & 7,793 & 7,793 & $31.9 \%$ \\
1 worker, 2 members & 17,037 & 8,519 & $25.8 \%$ \\
1 worker, 3 or more members & 21,115 & 5,969 & $18.6 \%$ \\
2 or more workers & 27,612 & 7,266 & $29.5 \%$ \\
\hline
\end{tabular}

In $\mathrm{kcal} / \mathrm{day}$

${ }^{\dagger}$ Includes only trips to work, not trips from work.

\section{Increasing Shopping Trip Energy Consumption}

In the Osaka metropolitan area in 1970, little energy was consumed by shopping trips; shopping trips were relatively short (13.2 minutes on average) and made mostly on foot or by bicycle (about $85 \%$ by non-motorized modes). Average shopping trip duration increased by $14 \%$ to 15.1 minutes in 2000 (Figure 1). The average trip duration for all trips increased by 9.2\%, from 23.2 minutes in 1970 to 25.3 minutes in 2000 (Figure 2).

For shopping trips, the rate of increase in energy consumption is much larger than that of trip duration. As Figure 3 shows, the average amount of energy consumed per shopping trip increased from $193 \mathrm{kcal} /$ trip in 1970 to $1116 \mathrm{kcal} /$ trip in 2000. The rate of increase in energy consumption, 5.78 times, is substantially larger than the rate of increase in trip duration seen above. The average energy consumption per trip for all trip purposes increased by $58 \%$ from 1333 to $2111 \mathrm{kcal} /$ trip (Figure 4). Obviously the rate of increase is disproportionally larger for shopping trips, partly because the base value for 1970 was quite small. 


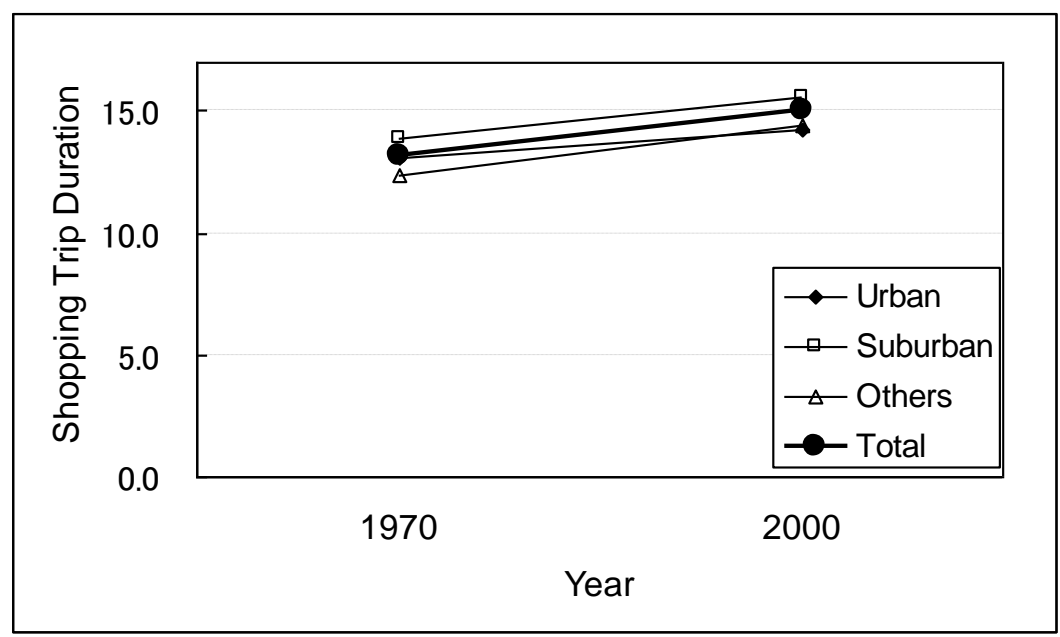

Figure 1. Mean Shopping Trip Duration by Residence Area: 1970 vs. 2000

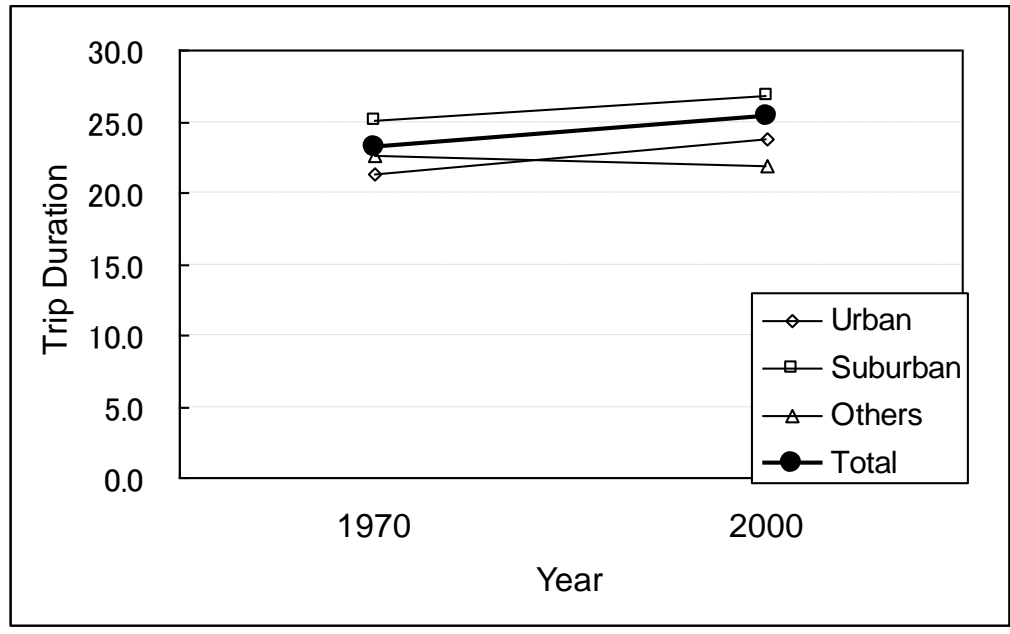

Figure 2. Mean Trip Duration by Residence Area: 1970 vs. 2000

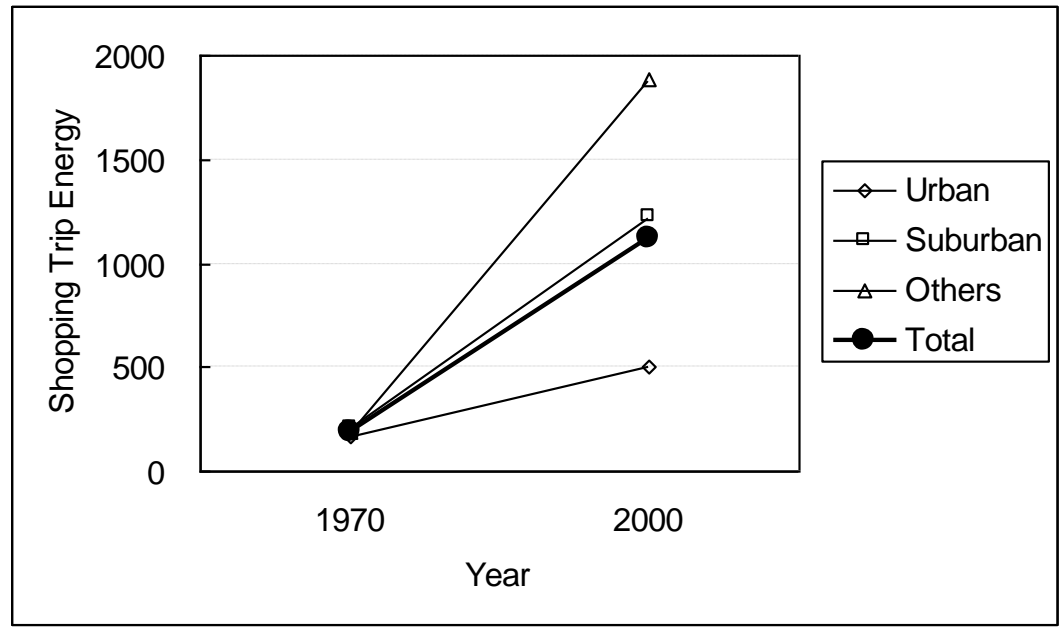

Figure 3. Mean Shopping Trip Energy Consumption by Residence Area: 1970 vs. 2000 
Residence area is associated with the rate of change in trip energy consumption between 1970 and 2000. No obvious trends can be seen from Figures 1 and 2 between residence area and trip duration, although they exhibit tendencies that suburban residents tended to have longer mean trip durations than urban residents. The effect of residence area on trip energy consumption, on the other hand, is obvious. While there were little differences among residence area types in 1970, the mean energy consumption by residents of "other" areas (unurbanized, unincorporated areas) grew much faster than those of residents in urban or suburban areas. Suburban residents also exhibit substantial increases, while the rate of increase is much smaller for urban residents.

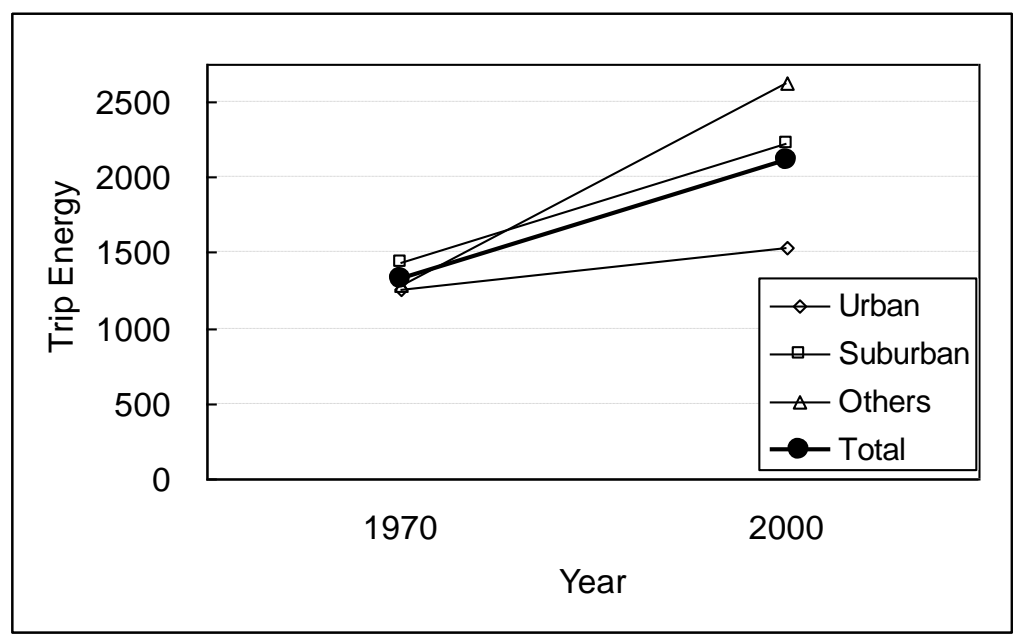

Figure 4. Mean Trip Energy Consumption by Residence Area: 1970 vs. 2000

The number of shopping trips per traveler ${ }^{5}$ increased by $16.9 \%$ from 0.277 to 0.324 trip/person/day between 1970 and 2000, indicating an increased level of shopping activities in 2000. Average household size, including non-travelers and minor members of less than five years old for whom no trips are recorded, decreased by $11.6 \%$ from 3.37 to 2.98 . As a result, the average number of shopping trips per household increased slightly from 0.710 to 0.731 trip per day. Nonetheless, household shopping trip energy consumption increased substantially from 137 to $816 \mathrm{kcal} /$ day. $^{6}$

\section{Reasons for the Increase in Shopping Trip Energy Consumption}

Conceivable reasons for the increase in shopping trip energy consumption mentioned in the previous sections are discussed here. They include: motorization, suburbanization, changes in gender roles, decreasing household size, and economic growth.

Motorization: As the discussions so far have alluded to, it is most likely that motorization is the principal factor that has contributed to the increase in shopping trip energy consumption. In Japan shopping was traditionally undertaken daily on foot in neighborhood shopping streets or corner grocery stores with minimal energy consumption (as noted earlier, walk trips

\footnotetext{
5 A traveler refers to a survey respondent who reported at least one trip on the survey day.

${ }^{6}$ The statistics here are slightly different from those presented in Section 1 as the samples used are not identical.
} 
and bicycle trips are treated to consume no energy in the analysis of this study). In 1970, $85.1 \%$ of shopping trips were made by non-motorized travel modes and the fraction of car trips was a mere $3.1 \%$ (Figure 5). Household members (typically non-employed adult female members of the household, who are often called "homemakers") went to neighborhood grocery stores everyday to acquire fresh produces and other products in small quantities to be consumed on the same day. The amount of purchase is limited by the fact that the acquired merchandise had to be carried home by hand.

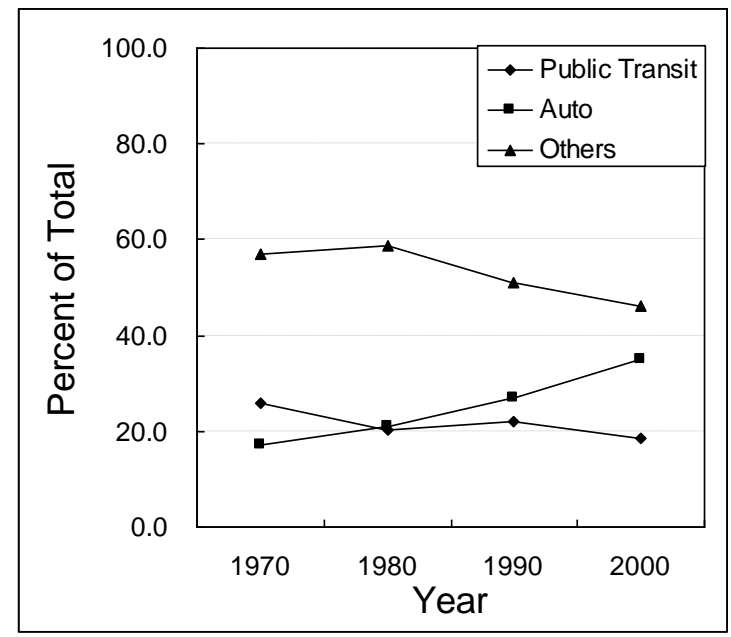

a. All Trips

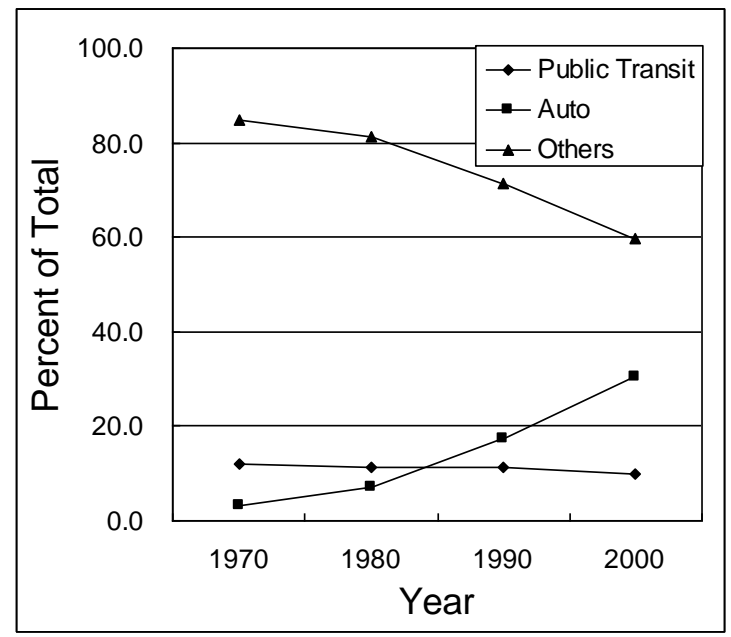

b. Shopping Trips

Figure 5. Trends in Mode Use 1970 through 2000: All Trips vs. Shopping Trips

Motorization - increases in ownership and use of the automobile-has changed all this. Starting in the 1960s, household vehicle ownership changed dramatically in a few decades that followed (Figure 6). Family cars are now used to travel to faraway large-scale supermarkets and discount stores with perhaps smaller frequencies but to acquire larger quantities at a time. Underlying this trend is the increase in driver's license holding by women, and developments of "roadside businesses"-location along highway corridors of stores and businesses catering primarily to auto users - both of which became prevalent in Japan in the 1980s,

Suburbanization: The Osaka metropolitan area developed along its rail networks, whose configuration had been well established by the Great Depression of 1929. A suburban community would develop around a railroad station as its nucleus, being contained within a walking distance from the rail station. As suburban communities expanded, bus lines were introduced to feed commuters to rail stations. Yet, the action space of non-working household members was still walk-based.

As homemakers acquired a driver's license and multi-auto ownership became prevalent, however, walk-based shopping at neighborhood stores or shopping streets around railroad stations were gradually replaced by visits by auto at suburban large-scale retail stores along highways. Quite interestingly, motorization progressed differentially between urban area and other (suburbs and non-urban) areas. Figure 7 shows that vehicle ownership increased much faster in other areas than in urban areas. In fact, in old, more central parts of the Osaka metropolitan area, modal split has virtually not changed between 1970 and 2000 (Kitamura et al., 2003). 


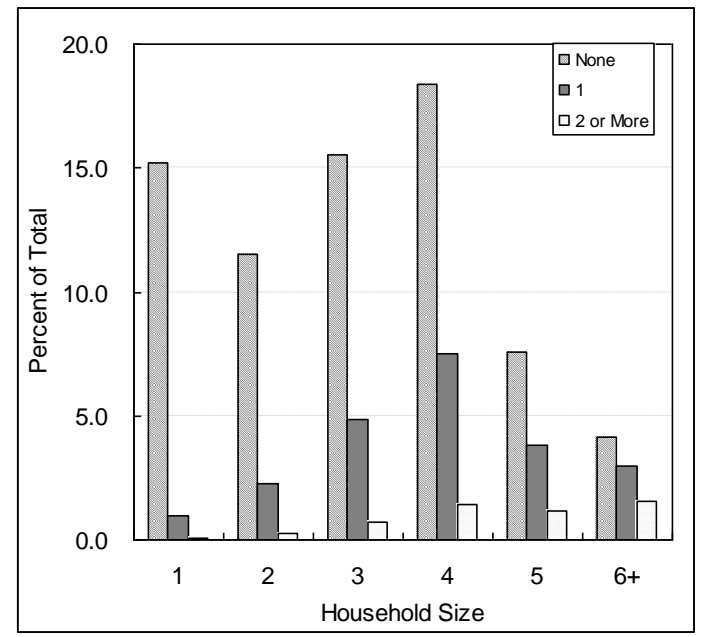

a. 1970

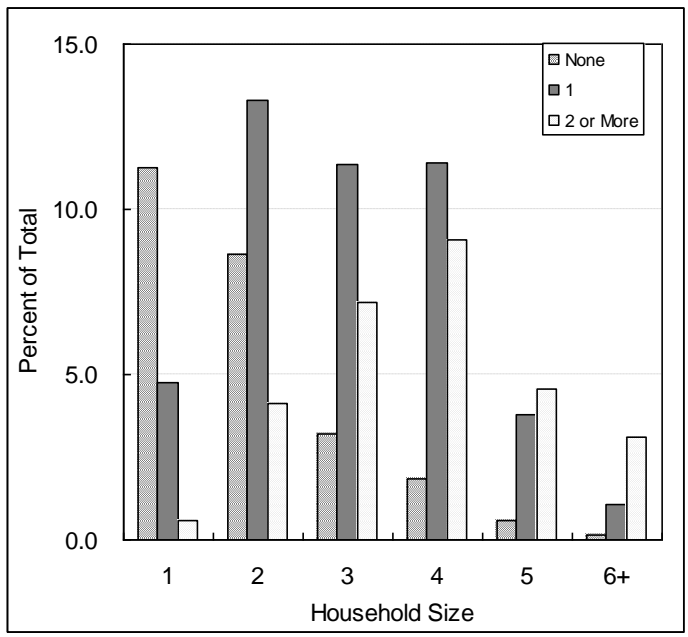

b. 2000

Figure 6. Distribution of Households by Vehicle Ownership and Household Size: 1970 vs. 2000

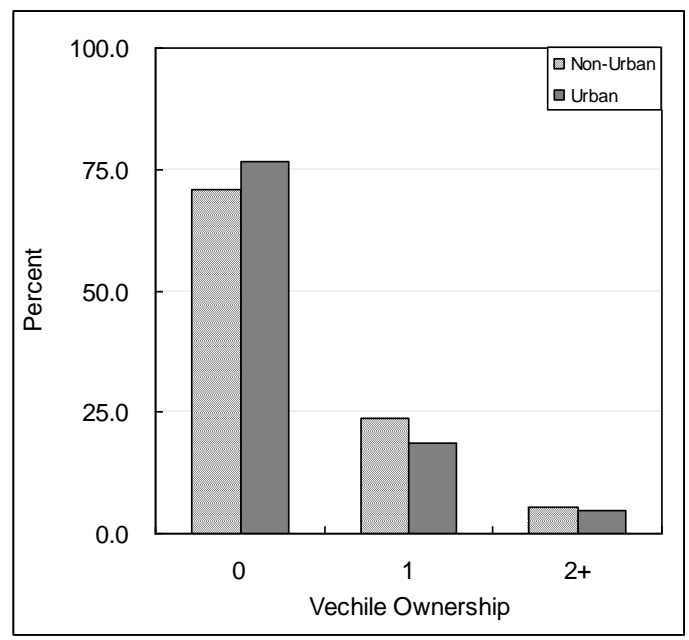

a. 1970

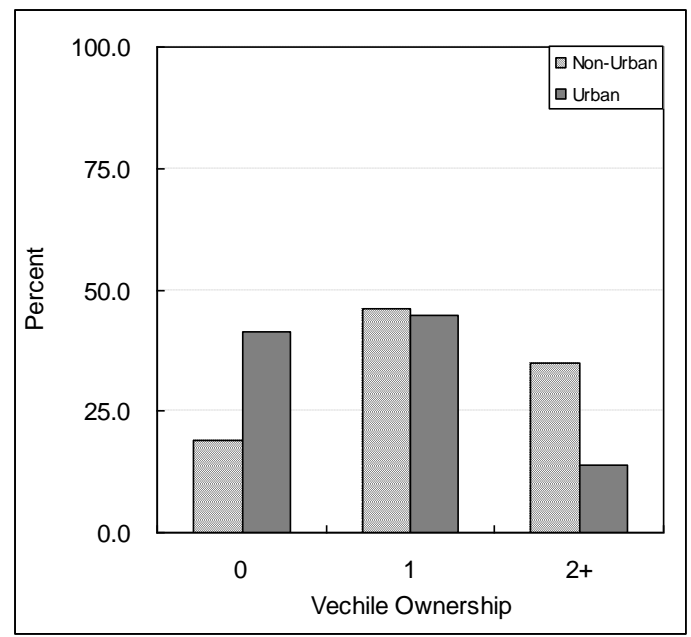

b. 2000

Figure 7. Vehicle Ownership by Residence Area: 1970 vs. 2000

Changing Gender Roles: As noted earlier, those who undertook the walk trips to neighborhood grocery stores were typically homemakers. Increasing labor force participation by women (Figure 8) has changed shopping patterns from frequent shopping in the neighborhood to acquire small quantities to less frequent shopping at remote large-scale retail stores to purchase large quantities. It is also the case that more shopping trips have become to be chained to female workers' commute trips. Facilitating these changes are motorization and emergence of suburban shopping opportunities as discussed earlier.

Declining Household Size: In case of a large household, shopping needs of its members can be consolidated and the task of shopping can be assigned to some member. It can be anticipated that shopping trip generation per person decreases with household size. The trend toward smaller households ongoing in Japan, then, is expected to have led to an increase in shopping trip generation per person. The increase in the average number of shopping trips per traveler from 0.277 in 1970 to 0.324 in 2000 is consistent with this conjecture, although 
further examination in multi-variate contexts is due to be conclusive.

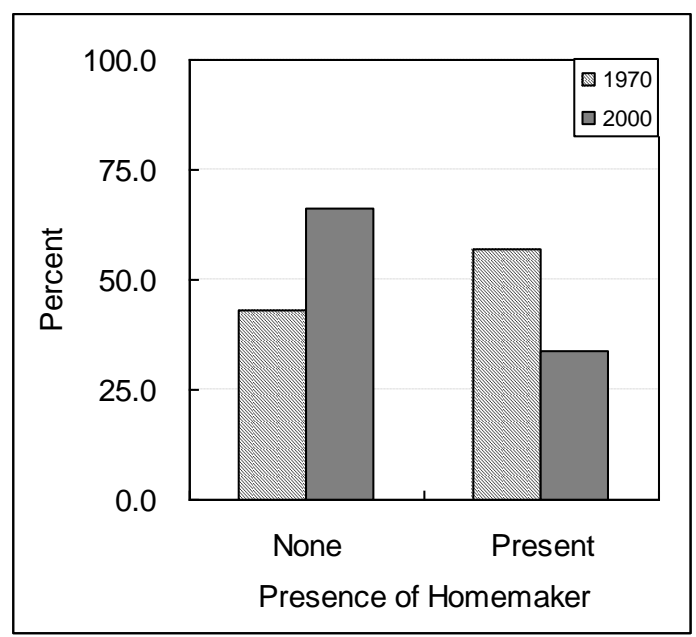

Figure 8. The Percentage of Households with Homemakers: 1970 vs. 2000

Economic Growth: Increasing real income and material affluence, resulting from economic growth, is expected to have contributed to increased shopping activities, and therefore to increased shopping trip generation and energy consumption.

This study is an attempt to statistically examine some of these hypothetical causalities using the empirical data from 1970 and 2000. The statistical method adopted is analysis of variance, whose design has been motivated by the discussions of this section.

\section{Analysis of Variance}

The descriptive statistics so far have indicated that motorization has contributed to the vast increase in shopping trip energy consumption between 1970 and 2000. It has also been seen that residence area is correlated with vehicle ownership and use. To isolate the effects on energy consumption of these factors, analysis of variance (ANOVA) is deployed in this study with

household shopping trip energy consumption, and

average shopping trip energy consumption per household member

used as the dependent variable. The factors of the analysis are (their categories in parentheses):

household size (1, 2, 3, 4, 5, 6 or more), number of vehicles available to household ( $0,1,2$ or more), presence of a homemaker in household (present, not present), residence area (urban, others), and year $(1970,2000)$.

Household size is introduced to capture the effect of declining household size on shopping trip energy consumption. Number of vehicles available to household represents the effect of 
motorization. Presence of a homemaker is intended to measure the effect of changing gender roles, while residence area is expected to represent the effect of suburbanization, and year is introduced to represent time effects, including economic effects. The results are summarized in Appendix Table.

As the discussions above have indicated, household size and vehicle ownership show small differences between urban and other areas in 1970. This is also the case with the set of factor levels adopted in this ANOVA exercise. In 2000, there are clear differences in vehicle ownership, with non-urban households owning more vehicles; and there are more smaller households in urban areas in 2000. Finally, there are substantially more households without a homemaker in 2000. In the discussions that follow, effects of these factors on shopping trip energy consumption per person are discussed. Similar results have been found for total shopping trip energy consumption by households as well. ${ }^{7}$

All main effects are extremely significant. In particular, number of vehicles available accounts for the largest fraction of variance, for both total household shopping trip energy consumption (results not shown) and shopping trip energy consumption per person. This is followed by presence of home maker and year in terms of mean sum of squares (sum of squares divided by the degrees of freedom).

Turning to the second-order effects, the most significant is the one involving number of vehicles available and year. For illustration purposes, this interaction effect is represented by two sets of number of vehicles main effects estimated for the respective years. As shown in Figure 9, a household with more vehicles available tended to consume more energy for shopping trips, both in 1970 and 2000. The magnitude of the effects, however, has changed very substantially between the two time points as the figure shows. The year-number of vehicles interaction is most significant and accounts for by far the largest fraction of total variation among the second-order interaction effects; the influence of auto ownership on shopping energy consumption has changed quite substantially between 1970 and 2000.

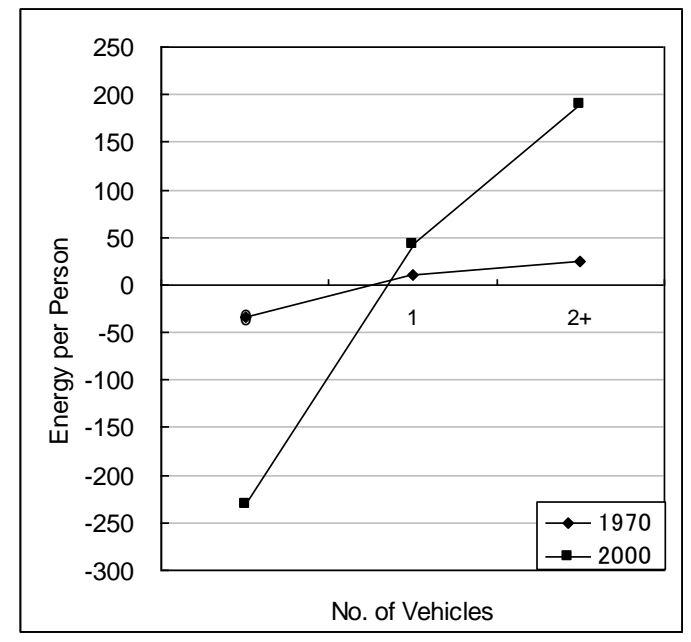

Figure 9. Main Effects of Vehicle Ownership by Year

\footnotetext{
7 Except that the negative association between household size and shopping trip energy consumption per person is not found between household size and total shopping trip energy consumption by household.
} 
The other second-order interaction effects involving year are also all very significant, and, like the year-number of vehicles interaction, indicate that the effect of a variable has intensified in year 2000. An example is shown in Figure 10 for household size. The trend that energy consumption per person decreases with household size remained the same, but very much intensified in year 2000. Likewise, a member from a household with a homemaker and one from a household residing in a non-urban area on average consumed more energy, both in 1970 and 2000. These effects have very much intensified in 2000 as well (Figures 11 and 12). In other words, changes over time of these factor effects can be found in their magnitude, not in their direction; changes are quantitative rather than qualitative.

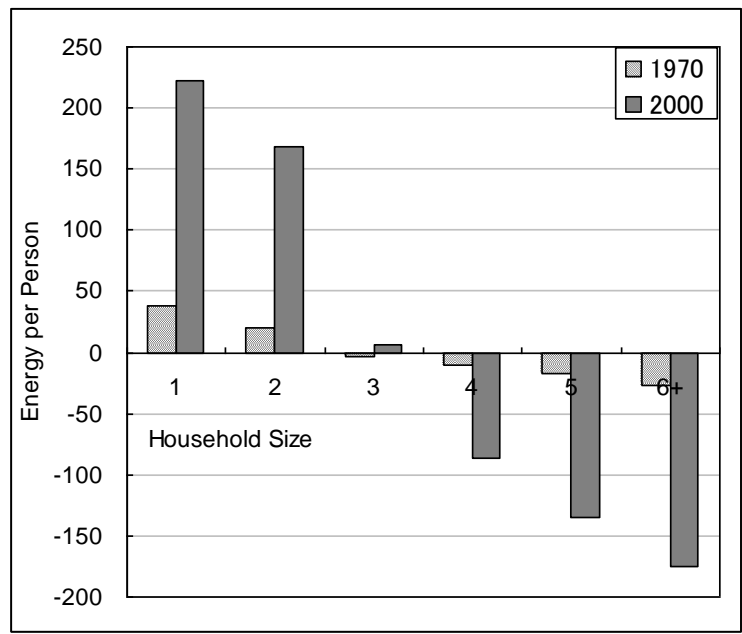

Figure 10. Main Effects of Household Size by Year

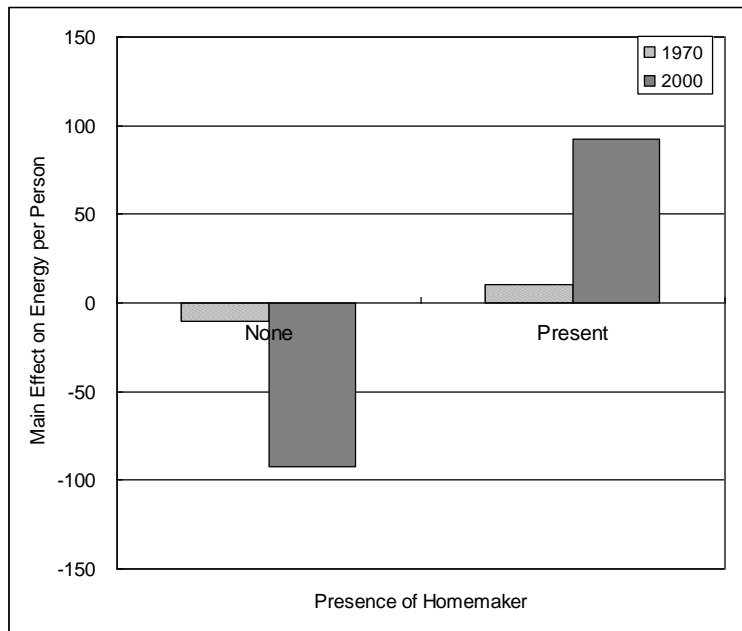

Figure 11. Main Effects of the Presence of Homemaker by Year

The magnitudes of the respective factors' effects are examined for the respective year by estimating regression models that exclude one of the factors at a time. A base regression model for each year represents fully specified ANOVA models for the respective years with up to fourth-order interaction terms involving household size, number of vehicles, presence of a homemaker, and residence area. A model that excludes those terms representing the main effect of a factor and the interaction effects that involve that factor is estimated and compared with the full model to evaluate the total effect of that factor. The results are summarized in Table 5 for energy consumption per person. 


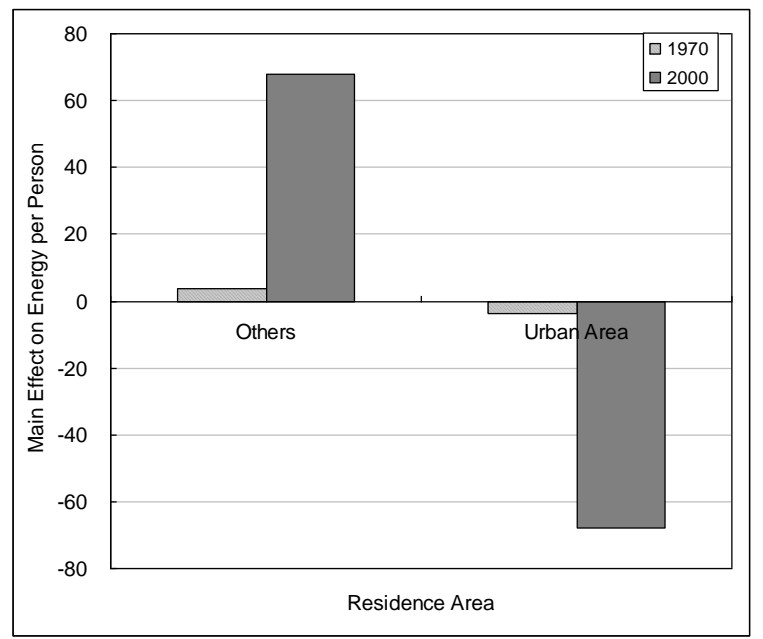

Figure 12. Main Effects of Residence Area by Year

The regression sum of squares (RSS) of each factor, except for household size, accounts for larger fractions of total sum of squares (TSS) in 2000 than in 1970. Consequently they are more significant, as the much larger $F$ statistics in the model for 2000 indicate. For the only exception, household size, the fraction explained reduced from $0.503 \%$ to $0.121 \%$, and the $F$ statistic from 9.05 to 3.09. Obviously household size in 2000 does not account for energy consumption per person as much as in 1970, possibly because there were not many large households ${ }^{8}$ and intra-household interaction and task-sharing has become less important in recent years.

Table 5. RSS Attributable to Respective Factors: Shopping Trip Energy Consumption per Household Member

\begin{tabular}{|l|r|r|r|r|r|r|c|}
\hline \multicolumn{1}{|c|}{ Factor } & $\begin{array}{c}\text { RSS of } \\
\text { Factor* }\end{array}$ & df & $\%$ of TSS & $\%$ of RSS & $F$ & df & $\mathrm{p}$ \\
\hline $1970(N=107,348)$ & & & & & & & \\
\hline Household Size & 64.9 & 60 & 0.503 & 65.24 & 9.05 & $(60,107276)$ & $<0.00005$ \\
\hline Vehicle Ownership & 75.0 & 48 & 0.583 & 65.89 & 13.15 & $(48,107276)$ & $<0.00005$ \\
\hline Homemaker & 226.8 & 36 & 0.204 & 23.00 & 6.12 & $(36,107276)$ & $<0.00005$ \\
\hline Urban Residency & 79.0 & 36 & 0.071 & 8.01 & 2.13 & $(36,107276)$ & 0.00009 \\
\hline 2000 $(N=146,820)$ & & & & & & & \\
\hline Household Size & 1390.2 & 60 & 0.121 & 2.69 & 3.09 & $(60,146748)$ & $<0.00005$ \\
\hline Vehicle Ownership & 19654.5 & 48 & 1.704 & 38.03 & 54.54 & $(48,146748)$ & $<0.00005$ \\
\hline Homemaker & 14665.1 & 36 & 1.271 & 28.37 & 54.26 & $(36,146748)$ & $<0.00005$ \\
\hline Urban Residency & 6224.5 & 36 & 0.540 & 12.04 & 23.03 & $(36,146748)$ & $<0.00005$ \\
\hline
\end{tabular}

* Divided by $1,000,000$

Another observation that can be made is that the percent of total RSS accounted for by each factor has decreased substantially in the 2000 results. It may be the case that there were positive correlations among factors (or with vehicle ownership) in 1970, which more than diminished in 2000. In any event, these factors account for a much larger fraction of TSS in 2000. Energy consumption for shopping trip tended to be influenced by random factors in 1970 ; it has become more systematic in 2000 .

${ }^{8}$ The fraction of households with four or more members in the sample of this study decreased form $48.6 \%$ in 1970 to $35.6 \%$ in 2000 . 
A question that arises is whether the increase in energy consumption found between 1970 and 2000 is due to changes in the effects of the respective factors, or due to changes in the distribution of factor levels in the sample. For example, is it due to the much increased effect of number of vehicles, or to the increased fraction of households with one or more vehicles. To examine this, the method in Kitamura and Susilo (2005) is followed and energy consumption is predicted using:

1970 factor effects and 1970 distribution of factor levels (replicates 1970 observation) 1970 factor effects and 2000 distribution of factor levels 2000 factor effects and 1970 distribution of factor levels 2000 factor effects and 2000 distribution of factor levels (replicates 2000 observation)

The results are summarized in Table 6.

Table 6. Decomposition of the Increase in Shopping Trip Energy Consumption to Factor Effects and Distribution of Factor Levels

\begin{tabular}{|c|ccc|}
\hline \multirow{2}{*}{$\begin{array}{c}\text { Factor Level } \\
\text { Distribution }\end{array}$} & \multicolumn{3}{|c|}{ Factor Effects } \\
\cline { 2 - 4 } & 1970 & & 2000 \\
\hline \multirow{2}{*}{1970} & $\frac{44.91}{\mid}$ & $-(\times 3.04) \rightarrow$ & 136.62 \\
& $(\times 1.67)$ & & $\mid$ \\
& $\downarrow$ & & $(\times 2.05)$ \\
& & & $\downarrow$ \\
2000 & 75.18 & $-(\times 3.73) \rightarrow$ & 280.16 \\
\hline
\end{tabular}

Table 6 indicates that structural change - change in the factor effects - has had more substantial effects on shopping trip energy consumption per person than has factor level distribution. With the 1970 distribution of factor levels, energy consumption would increase by 3.04 times if factor effects changes from those of 1970 to those of 2000; with the 2000 distribution of factor levels, it would increase by 3.73 times. With the 1970 factor effects, on the other hand, there would be a 1.67-fold increase in energy consumption when the distribution of factor levels shifts from that of 1970 to that of 2000. The corresponding figure with the 2000 factor effects is 2.05 . These two types of increase combine themselves to yield the over six-fold increase in energy consumption per person, from $44.9 \mathrm{kcal} /$ day to 280 $\mathrm{kcal} / \mathrm{day}$.

The result implies that the shopping trip energy consumption by a member of a household with a given combination of factor levels on average increased over three times between 1970 and 2000. In other words, even when there was no progress in motorization, no reduction in household size, or no decline in the fraction of households with a homemaker, energy consumption would have increased over three-fold in these three decades. Although it is difficult to determine the source of this structural change, it is very plausible that prevailing automobility — changes in the urban system in all its aspects, including land use, transportation and distribution, retailing, consumer products, etc., to cater to the increasing ownership and use of the automobile - is the single most significant element comprising this structural change. 


\section{Conclusions}

The increase in shopping trip energy consumption in the Osaka metropolitan area of Japan between 1970 and 2000 has been examined in this study. Energy consumption for shopping trips has increased with a much larger rate than that for trips for all purposes. Underlying this is the change in shopping behavior, from foot-based visits to neighborhood shopping streets or grocery stores to auto-based visits to faraway large-scale retail stores. Underlying this phenomenon are many changes: progress of motorization, declining household size, and diminishing households with a homemaker, among others.

The study has shown that these changes alone would not have produced the observed increase in shopping trip energy consumption. In fact structural change has been more substantial; the ANOVA analysis of this study has indicated that energy consumption would have increased over three-fold even when none of these changes in demographics and socio-economics had taken place. It is conjectured that this structural change is due to prevailing automobility, i.e., the urban system adjusting its elements-land use, transportation networks, facility location, retail systems etc. - to adapt to increased ownership and use of the automobile. The analysis of this study has shown that this structural change would have yielded an over three-fold increase in shopping trip energy consumption per person. This, combined with changes in demographics and socio-economics, has resulted in the over six-fold increase in energy consumption.

Further to the three-fold energy increase due to structural changes, the length of the trips has increased by $14 \%$ as behavioral and structural changes have moved away from non-motorized travel. Although the time change is minimal, the change in energy consumption is considerable. Further, the number of trips has increased by $16.9 \%$, though the decrease in household size by $11.6 \%$ may partially account for this.

This research suggests that urban form that has mixed land use and is suited to non-motorized travel consumes much less energy as well as time. Further consider prior research by Susilo and Kitamura (2005) where transit-commuters were more mobile and had higher levels of activity engagement compared to auto-commuters. Such research contradicts theories by Gordon and Richardson that "the link between high-density development and reduced VMT (vehicle miles traveled), and hence reduced energy consumption, is by no means clear."

As an indication of sustainability, this study showed that structural changes alone have caused significant increases in energy use. In this respect, the area is moving away from sustainability as behavior and development become more auto-oriented. The analysis has led to the conjecture that prevailing automobility is the more substantial contributor to this decline than changes in household characteristics. The automobility itself, however, has not been well quantified in this study. This remains as a future research subject.

\section{References}

Crane, Randall and Richard Crepeau (1998) Does Neighborhood Design Influence Travel?: A Behavioral Analysis of Travel Diary and GIS Data. Transportation Research, Part D: Transport and Environment, 3(4), 225-238.

Ewing, Reid (1997) Is LA-Style Sprawl Desirable? Journal of American Planning 
Association, 63(1), 107.

Fukui, Kenichiro (2003) Longitudinal Analysis of Travel Behavior Change Using Dynamic Urban Area Classification. MS thesis, Department of Civil Engineering Systems, Kyoto University, Kyoto, February (in Japanese).

Gordon, Peter and Harry Richardson (1997) Are Compact Cities Desirable? Journal of American Planning Association, 63(1), 95-107.

Kitamura, Ryuichi and Yusak O. Susilo (2005) Is travel demand insatiable? A study of changes in structural relationships underlying travel. Transportmetrica, 1(1), 23-45.

Kitamura, Ryuichi, Yusak O. Susilo, Kenichiro Fukui, Joe Murakami and Keiichi Kishino (2003) The invariants of travel behavior: the case of Kyoto-Osaka-Kobe metropolitan area of Japan, 1970-2000. Paper presented at the 10th Conference of the International Association or Travel Behaviour Research, Lucerne, August.

Litman, Todd (2005) Well Measured: Developing Indicators for Comprehensive and Sustainable Transport Planning. Victoria Transport Policy Institute.

Matsuhashi, K. (2000) A study on the compact city in view of regional trip energy in Osaka metropolitan area. Journal of the City Planning Institute of Japan, 35, $469-74$ (in Japanese).

Newman, Peter and Jeffrey Kenworthy (1999) Sustainability and Cities: Overcoming Automobile Dependence. Island Press.

Susilo, Yusak O. and Ryuichi Kitamura (2007) Structural changes in commuters' daily travel: The case of auto and transitcommuters in the Osaka metropolitan area of Japan, 1980 through 2000. Transportation Research, Part A (under review).

Urry, John (2005) The 'system' of automobility. In M. Featherstone, N. Thrift and J. Urry (eds.) Automobilities, SAGE Publications, London, pp. 25-39. 
Appendix Table. ANOVA Results:

1970/2000 Shopping Trip Energy Consumption per Person

\begin{tabular}{|c|c|c|c|c|c|c|}
\hline Effect & SS & $\% \mathrm{TSS}$ & df & MS & $F$ & $p$ \\
\hline Main Effects & 7127423197 & 3.88 & 10 & 712742320 & 1042.51 & 0.00000 \\
\hline Year (Y) & 783908466 & 0.43 & 1 & 783908466 & 1146.60 & 0.00000 \\
\hline Household Size (HS) & 1379554000 & 0.75 & 5 & 275910800 & 403.57 & 0.00000 \\
\hline Number of Vehicles Available (NV) & 1926310856 & 1.05 & 2 & 963155428 & 1408.78 & 0.00000 \\
\hline Presence of Homemaker (HM) & 787640365 & 0.43 & 1 & 787640365 & 1152.06 & 0.00000 \\
\hline Urban Resident (UR) & 407833658 & 0.22 & 1 & 407833658 & 596.53 & 0.00000 \\
\hline 2nd-Order Interaction Effects & 2268622010 & 1.24 & 34 & 66724177 & 97.60 & 0.00000 \\
\hline $\mathrm{Y} \times \mathrm{HS}$ & 168935589 & 0.09 & 5 & 33787118 & 49.42 & 0.00000 \\
\hline $\mathrm{Y} \times \mathrm{NV}$ & 386747730 & 0.21 & 2 & 193373865 & 282.84 & 0.00000 \\
\hline $\mathrm{Y} \times \mathrm{HM}$ & 45306442 & 0.02 & 1 & 45306442 & 66.27 & 0.00000 \\
\hline $\mathrm{Y} \times \mathrm{UR}$ & 47529186 & 0.03 & 1 & 47529186 & 69.52 & 0.00000 \\
\hline $\mathrm{HS} \times \mathrm{NV}$ & 236175484 & 0.13 & 10 & 23617548 & 34.54 & 0.00000 \\
\hline $\mathrm{HS} \times \mathrm{HM}$ & 117004818 & 0.06 & 5 & 23400964 & 34.23 & 0.00000 \\
\hline $\mathrm{HS} \times \mathrm{UR}$ & 87015761 & 0.05 & 5 & 17403152 & 25.46 & 0.00000 \\
\hline $\mathrm{NV} \times \mathrm{HM}$ & 230679638 & 0.13 & 2 & 115339819 & 168.70 & 0.00000 \\
\hline $\mathrm{NV} \times \mathrm{SR}$ & 138248619 & 0.08 & 2 & 69124310 & 101.11 & 0.00000 \\
\hline $\mathrm{HM} \times \mathrm{SR}$ & 42658873 & 0.02 & 1 & 42658873 & 62.40 & 0.00000 \\
\hline 3rd-Order Interaction Effects & 359941760 & 0.20 & 52 & 6921957 & 10.12 & 0.00000 \\
\hline $\mathrm{Y} \times \mathrm{HS} \times \mathrm{NV}$ & 60300372 & 0.03 & 10 & 6030037 & 8.82 & 0.00000 \\
\hline $\mathrm{Y} \times \mathrm{HS} \times \mathrm{HM}$ & 20292956 & 0.01 & 5 & 4058591 & 5.94 & 0.00002 \\
\hline $\mathrm{Y} \times \mathrm{HS} \times \mathrm{UR}$ & 5771040 & 0.00 & 5 & 1154208 & 1.69 & 0.13355 \\
\hline $\mathrm{Y} \times \mathrm{NV} \times \mathrm{HM}$ & 49446553 & 0.03 & 2 & 24723276 & 36.16 & 0.00000 \\
\hline $\mathrm{Y} \times \mathrm{NV} \times \mathrm{UR}$ & 24936570 & 0.01 & 2 & 12468285 & 18.24 & 0.00000 \\
\hline $\mathrm{Y} \times \mathrm{HM} \times \mathrm{UR}$ & 3410649 & 0.00 & 1 & 3410649 & 4.99 & 0.02552 \\
\hline $\mathrm{HS} \times \mathrm{NV} \times \mathrm{HM}$ & 34035243 & 0.02 & 10 & 3403524 & 4.98 & 0.00000 \\
\hline $\mathrm{HS} \times \mathrm{NV} \times \mathrm{UR}$ & 39880631 & 0.02 & 10 & 3988063 & 5.83 & 0.00000 \\
\hline $\mathrm{HS} \times \mathrm{HM} \times \mathrm{UR}$ & 4133689 & 0.00 & 5 & 826738 & 1.21 & 0.30175 \\
\hline $\mathrm{NV} \times \mathrm{HM} \times \mathrm{UR}$ & 8683299 & 0.00 & 2 & 4341650 & 6.35 & 0.00175 \\
\hline 4th-Order Interaction Effects & 40406080 & 0.02 & 37 & 1092056 & 1.60 & 0.01195 \\
\hline $\mathrm{Y} \times \mathrm{HS} \times \mathrm{NV} \times \mathrm{HM}$ & 16159895 & 0.01 & 10 & 1615989 & 2.36 & 0.00863 \\
\hline $\mathrm{Y} \times \mathrm{HS} \times \mathrm{NV} \times \mathrm{UR}$ & 5587033 & 0.00 & 10 & 558703 & 0.82 & 0.61204 \\
\hline $\mathrm{Y} \times \mathrm{HS} \times \mathrm{HM} \times \mathrm{UR}$ & 491504 & 0.00 & 5 & 98301 & 0.14 & 0.98191 \\
\hline $\mathrm{Y} \times \mathrm{NV} \times \mathrm{HM} \times \mathrm{UR}$ & 4216942 & 0.00 & 2 & 2108471 & 3.08 & 0.04578 \\
\hline $\mathrm{HS} \times \mathrm{NV} \times \mathrm{HM} \times \mathrm{UR}$ & 13273931 & 0.01 & 10 & 1327393 & 1.94 & 0.03530 \\
\hline 5th-Order Interaction Effects & 2288058 & 0.00 & 10 & 228806 & 0.33 & 0.97205 \\
\hline Model SS & 9798681107 & 5.34 & 143 & 68522246 & 100.23 & 0.00000 \\
\hline Error SS & 173671726623 & 94.66 & 254024 & 683682 & & \\
\hline Total SS & 183470407730 & 100.00 & 254167 & 721850 & & \\
\hline
\end{tabular}

Notes: The total effect of the set of interaction terms of each order is determined as the difference between the SSR of the linear regression model that includes that set of interaction effects and the complete sets of effects of lower order, and the SSR of the model that does not include that set of interaction effects.

The SS of each effect is determined as the difference between the SSR of the linear regression model that includes the complete set of effects of the same order and those of lower orders, and the regression model that exclude that effect. 